\title{
Categorías de emigrantes y líneas de acción en el sector público nicaragüense
}

José Luis Rocha

Servicio Jesuita para Migrantes - Nicaragua. Universidad Centroamericana, Managua. Correo electrónico: jlrochag@yahoo.com, jlrochag@ns.uca.edu.ni

ESTE ARTÍCULO OFRECE APORTES A LAS POLÍTICAS MIGRATOTRIAS proporcionando información sobre el estado de las migraciones, las necesidades de distintas categorías de migrantes y el rol de distintas organizaciones estatales y sus tareas, al tiempo que explicitan o sugieren conexiones entre unas y otras. Su propósito es identificar necesidades, sugerir colaboraciones, rescatar la relación con los planes de desarrollo, revelar problemáticas derivadas de distintas situaciones migratorias, y finalmente proponer esbozos de programas que sean respuestas específicas y en los que se pueda ver actuar al unísono a las organizaciones a las cuales les compete la gestión de migraciones internacionales. La finalidad del conjunto es proponer una gestión migratoria que disminuya los efectos perniciosos y multiplique las consecuencias benéficas de las migraciones.

Palabras clave: migraciones / políticas migratorias

\section{Introducción}

La efectividad de la gestión de las migraciones depende de que ésta responda a las necesidades existentes. La variedad de programas y normativas debe corresponder a la diversidad de problemáticas, que es imprescindible desentrañar y distinguir. Las distinciones posibilitan diseñar políticas de regulación de los flujos, políticas de integración, políticas hacia el retorno, políticas de admisión y políticas de protección en el extranjero. Discernir los eventos es un paso elemental para producir políticas mejor enfocadas. Profundizaremos en las diversas categorías de migrantes y sus problemáticas para después proponer algunos programas específicos de atención a los mismos en distintas entidades estatales. De esta forma se hará evidente que esos programas están abocados a responder a diversos ámbitos y dimensiones de las migraciones.

\section{Categorías de emigrantes}

\subsection{Migrantes en tránsito}

Los migrantes en tránsito requieren especial atención. Mujeres y hombres que deciden abandonar Nicaragua son víctimas de abusos de las autoridades y de los delincuentes 
comunes durante su camino. Diversos factores aumentan su indefensión y vulnerabilidad: el llevar algún dinero, necesario para los gastos de viaje y alojamiento; la necesidad de pasar inadvertidos; el desconocimiento de la geografía y el ámbito social y cultural por el que transitan; la incapacidad para reconocer a las autoridades y sus ámbitos de competencia; la ignorancia de sus derechos más elementales y la necesidad de recurrir a agentes poco escrupulosos que emplean medios ilegales y en extremo riesgosos para la vida de los migrantes.

Honduras, Guatemala y, especialmente México, constituyen la extensa frontera vertical que deben atravesar los nicaragüenses que se dirigen hacia los Estados Unidos. A lo largo de su trayecto muchos son aprehendidos, desaparecidos, asesinados y prostituidos. Las más vulnerables son las mujeres. Es imprescindible que el gobierno nicaragüense, en conjunto con los gobiernos centroamericanos, negocie con México acuerdos que garanticen los derechos de los migrantes en tránsito. Guatemala es el único país del área que ha suscrito acuerdos con los mexicanos (OIM, 2005). La protección consular y la operativización eficiente de consulados móviles de los países centroamericanos a lo largo de la región podrían jugar aquí un papel destacado. Las redes de la sociedad civil podrían facilitar flujos de información y denuncias.

Por otra parte, el Estado de Nicaragua también tiene que velar por el respeto a los derechos de los migrantes que atraviesan su territorio. Nicaragua es un país de fácil tránsito debido a los acuerdos tomados por las autoridades migratorias al eliminar los requisitos de visado a diversas nacionalidades. Con la globalización de las migraciones y debido a su posición geográfica, Nicaragua ha visto incrementarse el flujo de migrantes que atraviesan su territorio rumbo a los Estados Unidos. La policía migratoria nicaragüense ha multiplicado los reembarcos, deportaciones y rechazos de extranjeros. En 2004, 711 ciudadanos de otros países fueron afectados por estas medidas. Entre 1996 y 2004, sumaron 8.119. En ese mismo período fueron retenidos 5.743 extranjeros, entre los que destacaba una mayoría de 2.156 peruanos, 1.604 ecuatorianos, 487 colombianos y 210 dominicanos (DGME, 2005). Entre los migrantes que transitan por Nicaragua no faltan los africanos -nigerianos y somalíes- y los asiáticos -chinos, indios y nepalíes- (OIM, 2000). La garantía de sus derechos es un reto para el Estado de Nicaragua.

En Nicaragua, el artículo 21 de la Ley 240 de Control del Tráfico de Migrantes Ilegales aprobada en noviembre de 1996, condenaba a tres meses de arresto y deportación a todo extranjero que ingresara al país de forma irregular. Esta ley establecía penas de cuatro a ocho años de prisión y multas de entre 10 mil y 50 mil córdobas aplicables a los traficantes (OIM, 2001).

La Red Nicaragüense de Organizaciones de la Sociedad Civil para las Migraciones promovió una reforma de esta Ley 240. Su propuesta tenía por objetivo hacerla acorde con la normativa internacional, que no discrimina a los indocumentados para el ejercicio de sus derechos. Las motivaciones principales de esta iniciativa giran en torno a la consideración de la precaria situación que impulsa a los migrantes a buscar mejores condiciones de vida en el extranjero y al hecho de que, siendo Nicaragua un país emisor de migrantes, sería inconsistente mantener una política dual que defienda los derechos de los connacionales 
en el exterior y atropelle los derechos de los migrantes extranjeros que transitan o se establecen en Nicaragua.

La Ley 513 de Reforma y Adición a la Ley 240, aprobada el 26 de noviembre de 2004, reduce el arresto de tres meses a una detención de 48 horas en el Centro Nacional de Retención de Migrantes y sus casos son puestos en conocimiento de su respectiva embajada o consulado, si las hubiere en el país, a fin de que esas instancias inicien el proceso de repatriación de los detenidos. A los traficantes, la reforma incrementó la pena-que era de cuatro a ocho años de prisión- a una privación de libertad de entre 5 y 10 años. La multa se transformó de entre 10 mil a 50 mil córdobas a entre 35 y 100 salarios mínimos. Para los encubridores, se mantuvo la pena de uno a cuatro años de prisión, pero en adelante se les aplicará una multa de 10 salarios mínimos en lugar de los 5 mil córdobas anteriormente establecidos. El cambio más revolucionario de la reforma se refiere a la posibilidad de que el matrimonio entre un migrante ilegal con un ciudadano o ciudadana nicaragüense le conceda el derecho a solicitar su estatus migratorio ante las autoridades competentes. La Ley 240 negaba el otorgamiento inmediato de ese derecho. La reforma establece que la unión de hecho estable por un período de al menos dos años convierte al migrante ilegal en acreedor de ese derecho.

Otro avance importante de esta reforma es la especificación de actividades tipificadas como tráfico de migrantes ilegales: la falsificación, suministro o posesión de documentos de viaje o de identidad falsos; la utilización, posesión o presentación de documentos falsos para introducir migrantes clandestinamente; y la organización o dirección de otras personas para que utilicen, posean o presenten documentos falsos o la participación como cómplices en dichos actos.

Muchos traficantes han sido y pueden ser detenidos por un lapso breve. Durante su corta detención, promotoras de la Asociación de Mujeres Nicaragüenses Luisa Amanda Espinoza (AMNLAE) acuden a las celdas e imparten charlas de sensibilización, instando a los traficantes a dar un trato digno a los migrantes que contratan sus servicios. El hecho de ser identificados por instituciones que trabajan con migrantes y sus familiares puede operar como una medida preventiva contra los abusos.

La Conferencia Regional sobre Migración ha puesto énfasis en el combate al tráfico ilegal de migrantes. La OIM ha realizado estudios de caso presentando a los migrantes como víctimas de los "coyotes" y sus redes, descritas insistentemente como vinculadas al narcotráfico y el crimen organizado. Los estudios de la OIM insisten en que por todo el mundo operan bandas internacionales organizadas para el tráfico de migrantes (OIM, s/fa,b,c,d,e,f).

Sin embargo, los traficantes no pueden ser subsumidos en bloque en una sola categoría. La asociación de los traficantes de personas con el narcotráfico no debe generalizarse. La insistencia en este vínculo, unida a otras afirmaciones criminalizadoras, tiende un velo sobre la realidad de que el tráfico ilegal de migrantes no está siendo llevado a cabo exclusiva ni mayoritariamente por redes de traficantes, sino por individuos que operan en forma aislada y poco sistemática, así como por familiares de los mismos migrantes. Este hecho sugiere que una política adecuada no debe poner el énfasis en un combate indiscriminado a los traficantes. Se precisa un esfuerzo para diferenciar ese mundo heterogéneo de facilitadores 
del tránsito, en el que encontramos desde simples vigilantes y conductores hasta guías que cubren todo el trayecto. Y aún entre éstos cabe distinguir entre quienes están motivados por el lucro y quienes realizan un servicio comunitario como parte de las redes sociales. La presentación de todos los traficantes en masa como individuos insertos en redes criminales de contrabandistas y narcotraficantes hace el juego a las abusivas políticas de control migratorio y a la ideología criminalizadora de las migraciones.

Poco se dice que el tráfico ilegal y los traficantes prosperan cuando las barreras y los controles a la migración son más severos y criminalizadores en los países de tránsito y destino. A más controles, mayores los costos que deben pagar los migrantes y peores los riesgos que corren durante su travesía (Massey y Espinosa, 1997:939-999). Mientras más férrea y de mayor cobertura es la vigilancia de las autoridades involucradas en el control migratorio, el tránsito debe realizarse por lugares más inhóspitos, donde los migrantes son frecuentemente presa fácil de los abusos y robos de delincuentes comunes o incluso de sus mismos baqueanos.

\subsection{Retornados}

Los retornados -forzados o no- son otra categoría que merece políticas específicas. Las repatriaciones de nicaragüenses que a inicios de la década de los noventa siguieron a la firma de los acuerdos de paz y el cese del conflicto bélico, encontraron al gobierno nicaragüense totalmente desprevenido, sin programas de reubicación y sin previsiones para manejar los conflictos sociales y ambientales derivados de la colisión entre los abruptos asentamientos espontáneos de población y las directrices de ordenamiento territorial.

El retorno y repatriación de flujos importantes de refugiados -que no siempre pudieron dirigirse a sus lugares de origen porque con frecuencia sus viviendas y parcelas habían sido ocupadas durante su ausencia o incluso reasignadas por el gobierno- sorprendió a la autoridad nicaragüense sin políticas adecuadas ni infraestructura institucional. El asentamiento en zonas que ulteriormente han sido declaradas reservas forestales hizo de estos retornados un problema visible, especialmente por los conflictos entre antiguos colonos, repatriados y desmovilizados (Nygren, 2000:807-830). En la zona de amortiguamiento de la reserva Indio-Maíz, los proyectos de reasentamiento y titulación de tierras se extendieron hasta la segunda mitad de la década de los noventa (Oficina de Ordenamiento Territorial/ DANIDA, 2000). En el norte de Nicaragua, el hecho de que entre los retornados procedentes de Honduras existiera una numerosa representación de poblaciones indígenas -mískitos y mayangnas- complejizó aún más la situación (Instituto de Investigaciones Itztani, 1989). A ello se añadió el problema de que algunos desplazados y sus familiares se asentaron en tierras que, además de haber sido demarcadas como reserva biológica, habían sido ocupadas tradicionalmente por mayangnas, erigidos en guardabosques por la cooperación alemana. Entre los re-establecidos mayangnas y los nuevos asentados -más depredadores en su relación con los recursos forestales- surgieron brotes de violencia que una política previsora pudo haber evitado.

En los últimos años, dentro del grupo de retornados es previsible que los deportados adquieran mayor importancia. La tendencia hacia el endurecimiento de las legislaciones y 
controles migratorios de los Estados Unidos y Costa Rica hace prever un próximo incremento de deportados.

En México, los nicaragüenses deportados han ido en aumento: 1.396 (2002), 2.043 (2003) y 1.564 sólo entre enero y agosto de 2004. Estas cifras palidecen frente a los deportados por México del resto de países centroamericanos en 2003: 81.361 guatemaltecos, 58.630 hondureños y 28.318 salvadoreños, datos que son sintomáticos de cuánto se han endurecido las políticas migratorias. ${ }^{1}$ Los controles se han reforzado significativamente en los últimos 30 años. México es la frontera vertical: filtra y merma el número de migrantes centroamericanos que buscan alcanzar los Estados Unidos. La cifra de nicaragüenses deportados es probablemente mayor, teniendo en cuenta que muchos centroamericanos se hacen pasar por guatemaltecos para no ser retornados tan al sur y, con menores costos, hacer un nuevo intento. La cantidad de expulsiones, deportaciones, devoluciones y rechazos de centroamericanos pasó de 1.472 en 1970 a 125.238 en 1999 (Castillo, 2000:144).

Aunque Nicaragua ha sido un país menos afectado por las deportaciones y relativamente más beneficiado por las naturalizaciones en los Estados Unidos que sus vecinos centroamericanos, con el endurecimiento de las políticas migratorias de los países de tránsito y destino es posible que las deportaciones se multipliquen. La Dirección General de Migración y Extranjería de Nicaragua calcula que en 2004 hubo 857 nicaragüenses reembarcados, deportados y rechazados por los Estados Unidos, es decir, más del doble que los 424 de 1996, los 263 de 1999 o los 386 de 2002. ${ }^{2}$ Entre 1992-1996 hubo sólo 1.585 nicaragüenses deportados desde los Estados Unidos, según las estadísticas oficiales del Servicio de Inmigración y Naturalización de ese país. Un promedio de 317 al año. Los nicaragüenses detenidos para ser deportados entre 1998-2004 fueron 7.745, un promedio de 1.106 por año. Aun así, estas cifras son insignificantes comparadas con los deportados de otros países centroamericanos (Immigration and Naturalization Service, 1996, 1998, 1999, 2000, 2001, 2002, 2003 y 2004).

Cuadro 1. Nicaragüenses, hondureños, guatemaltecos y salvadoreños deportados y naturalizados en los Estados Unidos

\begin{tabular}{|l|r|r|r|r|}
\hline País & $\begin{array}{c}\text { Deportados } \\
\text { de 1992 a 1996 }\end{array}$ & $\begin{array}{c}\text { Naturalizados } \\
\text { de 1992 a 1996 }\end{array}$ & $\begin{array}{c}\text { Deportados } \\
\text { de 1998 a 2004 }\end{array}$ & $\begin{array}{c}\text { Naturalizados } \\
\text { de 1998 a 2004 }\end{array}$ \\
\hline El Salvador & 9,767 & 57,695 & 87,013 & 102,031 \\
\hline Guatemala & 7,276 & 24,311 & 64,312 & 49,420 \\
\hline Honduras & 9,497 & 15,606 & 106,826 & 26,455 \\
\hline Nicaragua & 1,585 & 19,586 & 7,745 & 29,282 \\
\hline
\end{tabular}

Fuente: Statistical Yearbook of the Immigration and Naturalization Service.

Los nicaragüenses han sido relativamente más beneficiados por las naturalizaciones que afectados por las deportaciones. Los porcentajes de nicaragüenses deportados sobre el número de sus connacionales naturalizados se mantienen muy por debajo de los calculados para Honduras, Guatemala y El Salvador. Pero, igual que en esos países, tienen una tendencia a subir. Aunque la posición relativa de Nicaragua -en el contexto centroamericano y en este ámbito- sea favorable, hay indicios de que las deportaciones desde los Estados Unidos y el número de deportados en relación al de naturalizados tienden a aumentar. 
Por otro lado, en Costa Rica las deportaciones de nicaragüenses se redujeron a 17 en 1998 , después de alcanzar los 1.686 en 1996. Pero en el 2000 llegaron a 822. A ellos hay que agregar a muchos de los rechazados, porque las autoridades de Costa Rica expulsan con frecuencia a nicaragüenses tramitando su repatriación como un rechazo, esto supone una ventaja porque al rechazado, a diferencia del deportado, no se le prohíbe el ingreso a Costa Rica en los diez años siguientes a su expulsión. Según la Dirección de Migración de Costa Rica, entre 1995-2000 fueron rechazados 308.942 nicaragüenses (CEPAL/OIM/BID, 2002:79). La Dirección General de Migración y Extranjería de Nicaragua estima que, entre 1996 y 2004, hubo 391.059 nicaragüenses rechazados, reembarcados y deportados desde Costa Rica. ${ }^{3}$ Las redadas en La Carpio, reconocidas por el sistema de justicia costarricense, ${ }^{4}$ provocaron tensiones entre los nicaragüenses en Costa Rica.

En cualquier caso, la pertinencia de una política hacia los retornados en la agenda gubernamental no se deriva exclusivamente de la magnitud de su volumen y de su ritmo de crecimiento, sino también de aspectos más cualitativos, como los problemas asociados a su reinserción, a la transferencia tecnológica, a la relación de las comunidades de retornados con el medio ambiente, a los cambios culturales que quienes regresan van introduciendo en las comunidades y a su participación activa en la dinámica social. La ratificación por parte del Estado de Nicaragua de la Convención internacional sobre la protección de los derechos de todos los trabajadores migratorios y de sus familiares supone el compromiso, según su artículo 67, de que "los Estados Partes interesados cooperarán de la manera que resulte apropiada en la adopción de medidas relativas al regreso ordenado de los trabajadores migratorios y sus familiares al Estado de origen cuando decidan regresar, cuando expire su permiso de residencia o empleo, o cuando se encuentren en situación irregular en el Estado de empleo" (ACNUR, Universidad Iberoamericana y Comisión Nacional de los Derechos Humanos, 2002:266).

Lo que compete a un Estado es el diseño de condiciones de recepción favorables, con garantía de sus derechos y facilidad para el trámite de documentos, así como de mecanismos para que superen la vulnerabilidad que caracteriza el retorno de muchos. Otros gobiernos centroamericanos tienen experiencias en este sentido. Los gobiernos de Guatemala, El Salvador y Honduras empezaron a implementar en 2002 un plan piloto para atender a los ciudadanos de esos tres países que estaban siendo deportados desde la ciudad de México por vía terrestre. Dichos países establecieron un mecanismo de colaboración para conducir a los repatriados hasta un albergue en la ciudad capital de Guatemala, donde recibían atención de diverso tipo y, previa comunicación y trámites con las embajadas respectivas, se les proporcionaba documentación y se les trasladaba a sus países de origen. Aun cuando el énfasis de este programa está en la devolución de los migrantes a sus países de origen de manera rápida y eficaz, es notable el hecho de que también sea segura y ordenada, y el logro de la cooperación fronteriza. Es un reconocimiento de que el enfoque debe ser regional, apoyándose en convenios y acciones de instancias extra-regionales.

El programa "Bienvenido a casa" existe en El Salvador desde 1999 y está catalogado como un programa de emergencia. Conocido formalmente como Programa de Atención a los Inmigrantes Salvadoreños (PAIS), "Bienvenido a casa" tiene por objetivo dar atención inmediata a los ciudadanos salvadoreños deportados de los Estados Unidos, asegurándoles 
su reinserción laboral y ofreciéndoles asistencia psicosocial y atención médica. Este programa es también un modelo de concertación de actividades complementarias efectuadas por diversos organismos, pues se estableció en el marco de una comisión integrada por el Ministerio de Relaciones Exteriores y el del Interior, la OIM, la Universidad Don Bosco, la Universidad Centroamericana José Simeón Cañas (UCA), Catholic Relief Services, el Arzobispado de la Iglesia Católica, la Iglesia Americana de El Salvador y la Asociación Nacional de la Empresa Privada (ANEP). Algo así se podría emprender en Nicaragua. En el futuro, una política de repatriación, con ofertas atractivas para que los migrantes regresen y se inserten de forma productiva en el país podría ayudar a su reintegración y a la recuperación de ese capital humano una vez perdido y ahora posiblemente acrecentado con los conocimientos adquiridos en el extranjero.

\subsection{Trabajadores migrantes temporales}

Estudiosos de las migraciones calculan que en el año 2000 alrededor de 105 mil nicaragüenses migraron temporalmente a Costa Rica. Esta cifra ha ido creciendo año con año. Se estima que sólo el sector agroexportador agrícola costarricense absorbe estacionalmente a 60 mil trabajadores nicaragüenses (CONPES, 2001:33). Acuden durante las temporadas de corte de caña, café, banano o melón. Alvarenga Venutolo (2000:47) estimó que el 75\% de las labores agrícolas en Costa Rica las realizan trabajadores originarios de Nicaragua y que las fincas bananeras suelen depender de un 40\% de mano de obra nicaragüense. Baumeister calcula que la mano de obra estacional nicaragüense es el 83\% de la fuerza laboral en el cultivo de caña de azúcar, el 75\% en el cultivo de frijoles, el 66,7\% en el de naranja, el 63,2 \% en el café, el 50 \% en el melón y el 45,7\% en el banano (Baumeister, 2006).

Lelio Mármora (2002:144-145), al analizar la oferta laboral migrante, distingue entre mano de obra supletoria (migrantes que desempeñan oficios en los cuales no existen suficientes nativos calificados), complementaria (migrantes que ocupan plazas que los nativos desprecian en busca de mejores posiciones), adicional (migrantes que aceptan empleos que los nativos rechazan debido a su baja remuneración), competitiva (migrantes que compiten por los mismos empleos que los nativos, cuando éstos podrían satisfacer la demanda) y marginal (migrantes que crean empleos marginales, ajenos al eje oferta-demanda).

La inserción laboral estacional de los nicaragüenses ha tenido históricamente un efecto supletorio, complementario y adicional en diversas ramas de la economía costarricense. En los cortes de café, la mano de obra de los migrantes nicaragüenses tiene una larga historia de suplir la escasa oferta de mano de obra costarricense. Desde 1960, el considerable aumento del área cultivada y el salto en la productividad de Costa Rica incrementaron la demanda de cortadores. En los años ochenta, los refugiados centroamericanos cubrieron esa demanda temporalmente. Al finalizar los conflictos armados, retornaron a sus países y la escasez de cortadores reapareció, con gran alarma de los empresarios costarricenses. La solución “permanente" vino de los migrantes nicaragüenses (Alvarenga, 2000:53).

Las afirmaciones indiscriminadas que resaltan el papel negativo de la mano de obra nicaragüense, aduciendo supuestos efectos competitivos o incluso marginales, carecen de fundamento. El gobierno de Nicaragua debe apelar al tipo de inserción y de efecto sobre el 
mercado de trabajo de los migrantes nicaragüenses, para que el gobierno de Costa Rica no adopte políticas migratorias simplistas aconsejadas por la peligrosa correlación bruta entre el número de inmigrantes y el número de nativos desempleados.

Entre Costa Rica y Nicaragua se han producido intentos que van más allá de las amnistías migratorias. Con pretensiones de fuerte impacto y alcance en el tiempo, el Ministerio del Trabajo, bajo la administración de Calderón Fournier, estableció un Convenio Marco de mano de obra migrante 1993. Los sujetos de dicho convenio fueron los trabajadores nicaragüenses temporales del sector agrícola, principalmente los cortadores de café y caña de azúcar. En consideración a que apenas el 10\% de los trabajadores estacionales nicaragüenses migraron acogiéndose a este convenio, fue extendido al sector de la construcción y al del trabajo doméstico.

Posteriormente, dentro del mismo convenio, la administración de José María Figueres creó la Tarjeta laboral (Decreto $\mathrm{N}^{0} .141$ del 26 de julio de 1995), destinada a regularizar principalmente la mano de obra nicaragüense empleada en labores agrícolas estacionales. En poco más de un año, 27.300 nicaragüenses tramitaron en la Dirección General de Migración y Extranjería el pasaporte especial requerido para obtener la "Tarjeta laboral". En la práctica, la tarjeta no cumplió con sus objetivos. Los requisitos establecidos para su tramitación redujeron sustancialmente el número de beneficiarios. La mayoría de los nicaragüenses carecían de certificados de nacimiento originales u otra identificación, indispensables para el pasaporte especial. El proceso lento y complicado de estos trámites elevó los costos de transacción. Esto fue reforzado por el hecho de que los empleadores costarricenses no ofrecieron ventajas a los trabajadores que migraban en el marco del convenio sobre quienes lo hacían de forma irregular. El gobierno de Costa Rica decidió suspender el convenio en 1997 (Acuña y Olivares, 1999).

Actualmente el gobierno de Nicaragua se colocó en la senda de regularizar las migraciones laborales temporales con el "Acuerdo sobre la puesta en marcha de una política laboral migratoria binacional entre Costa Rica y Nicaragua”. Suscrito el 21 de enero de 2005 por los Ministros del Trabajo de Nicaragua y Costa Rica, este acuerdo reconoce como positivos los efectos de las migraciones ordenadas y señala la necesidad de que se garantice el respeto a los derechos humanos de los migrantes nicaragüenses en Costa Rica, de manera que gocen de las mismas condiciones que los trabajadores costarricenses. A fin de avanzar en esa dirección, dichos ministros aprobaron una matriz de trabajo para administrar los flujos migratorios, encaminada a adoptar una agenda acorde con las políticas públicas de empleo en ambos países y respetuosa de los principios de la OIT.

La promoción de permisos temporales, en el marco de una regulación de las migraciones estacionales, podría proporcionar a los migrantes una oportunidad de trabajo, ingresos y protección social libre de las tensiones y riesgos que la condición de indocumentados entraña durante el tránsito y la estadía. A los empleadores se les facilitaría una mano de obra adecuada y oportuna bajo el compromiso de cumplir con sus obligaciones. Nicaragua instalaría los canales para satisfacer la demanda de empleo de sus pobladores y podría garantizar que los derechos de sus connacionales sean respetados. Costa Rica, los Estados Unidos, o incluso Canadá y otros países, podrían satisfacer su demanda de mano de obra y 
ofrecer igualdad de condiciones a nacionales y extranjeros, ahorrando los recursos antes invertidos en controles migratorios.

Canadá tiene una larga tradición de migraciones temporales regulares. Los trabajadores temporales pioneros fueron jamaiquinos que comenzaron a llegar en 1966 con el Programa para los Trabajadores Agrícolas Temporales, conocido como SAW (siglas en inglés de "Seasonal Agricultural Workers"). En 1974, se extendió el programa a los trabajadores mexicanos y después se sumaron trabajadores de Trinidad y Tabago, Barbados y la Organización de los Estados Caribeños del Este. El programa SAW es un acuerdo entre Canadá y los países de origen de los trabajadores temporales. Este acuerdo determina los derechos y las responsabilidades de los trabajadores y de sus patrones, está autorizado por el gobierno federal a través del Departamento de Recursos y Desarrollo Humano de Canadá y es administrado por el Servicio de Administración de los Recursos Agrícolas Extranjeros. Los países que proporcionan los trabajadores temporales tienen el derecho de seleccionarlos. Actualmente el programa SAW opera en Alberta, Québec, Manitoba, Nueva Escocia, Nuevo Brunswick, La Isla del Príncipe Eduardo y Ontario, que recibe el 90\% de los trabajadores. Anualmente llegan a Canadá aproximadamente unos 15.000 trabajadores agrícolas temporales del Caribe y México para trabajar en los campos, huertos e invernaderos. Se está planificando extender este tipo de programa para "trabajadores invitados" a otros sectores como las industrias de la construcción, la hostelería y el turismo.

Guatemala y México están implementando un proyecto -con el financiamiento de la OIMcuya finalidad es contribuir al inicio del sistema informático de registro y control del flujo migratorio laboral. El proyecto contempla: descentralización de los programas fronterizos del Ministerio de Trabajo; un sistema de información sobre el flujo de trabajadores migrantes; una bolsa electrónica de empleo en las zonas fronterizas; una identificación única del trabajador migrante; ejecución de reuniones y talleres que promuevan la concientización de empleadores de trabajadores migrantes en relación al respeto y cumplimiento de los acuerdos bilaterales (Guatemala -México) en materia laboral y derechos humanos de los migrantes; propiciar el funcionamiento del observatorio del mercado laboral en la zonas fronterizas; y fortalecer la capacidad de gestión de los consulados guatemaltecos en el sur de México, en apoyo a los trabajadores migrantes (OIM, 2005).

Con la gestión de este tipo de proyectos, el Estado nicaragüense podría velar por el acceso a diversos servicios de sus conciudadanos que migran temporalmente. El Instituto Guatemalteco de Seguridad Social y el Ministerio de Salud Pública y Asistencia Social impulsan en dicho país el Programa de Protección Social al Trabajador Agrícola Migrante. Con el apoyo de la Organización Panamericana de la Salud y la Organización Mundial de la Salud, este programa propone dar satisfacción a la demanda de servicios de salud de los trabajadores temporales en los lugares de origen y de destino. Hasta el 2002, el programa benefició a 50 mil trabajadores migrantes, sus esposas e hijos menores de 5 años.

Conviene tener presente que el acceso a servicios sociales sólo se puede negociar abordando otros aspectos y disponiendo de mayor información. Los mercados laborales binacionales requieren el establecimiento de acuerdos formales orientados a proteger no solamente los derechos de los migrantes, sino también los intereses de otros actores afectados y los 
intereses de ambos países. Un manejo adecuado de las migraciones temporales descansa sobre dispositivos que permitan una regulación de las distintas dimensiones de los flujos de personas: magnitud, composición, destinos, períodos de duración, actividades a realizar en los lugares de destino, requerimientos de servicios sociales, cotizaciones en el seguro social, entre otras.

\subsection{Migrantes asentados}

El número de migrantes que se asientan en Costa Rica va creciendo, no así el ejercicio de sus derechos. Las reacciones xenofóbicas son comunes incluso entre los intelectuales, que ven en la presencia de migrantes nicaragüenses una amenaza a la identidad nacional costarricense (Sandoval, 2004:434-445). Diversos estudios han demostrado que con frecuencia los patrones no reportan a los migrantes a la Caja Costarricense del Seguro Social. Las denuncias de estas anomalías son mínimas porque los nicaragüenses indocumentados asumen que su situación migratoria irregular los excluye de los beneficios de la seguridad social. La Caja da cuenta de que el 40,5\% de los nicaragüenses registrados por el censo de 2000 -con más de seis meses de residir en Costa Rica- no están asegurados (Caja Costarricense del Seguro Social, 2004).

Esta situación es más grave para las mujeres, situadas en la base de la pirámide laboral y expuestas a salarios inferiores (Acuña, 2004). Las mujeres nicaragüenses que trabajan en el servicio doméstico en Costa Rica reciben casi 32\% menos salario que sus colegas costarricenses (OIM, 2001:23). Muchas de ellas viven durante años sin documentos, prácticamente recluidas en sus centros de trabajo, porque ni siquiera disponen de los documentos que las acreditan como ciudadanas nicaragüenses.

La situación irregular de muchos migrantes nicaragüenses multiplica las penurias y abusos mencionados. La ratificación de la Convención internacional sobre la protección de los derechos de todos los trabajadores migratorios y de sus familiares compromete al Estado de Nicaragua con la negociación de convenios de regularización. Según el artículo 69 de dicho instrumento: "Cuando los Estados Partes interesados consideren la posibilidad de regularizar la situación de dichas personas de conformidad con la legislación nacional y los acuerdos bilaterales y multilaterales aplicables, se tendrán debidamente en cuenta las circunstancias de su entrada, la duración de su estancia en los Estados de empleo y otras condiciones pertinentes, en particular las relacionadas con su situación familiar" (ACNUR et al., 2002:267). Y aunque los Estados de destino de los emigrantes nicaragüenses no han ratificado dicha convención, existen precedentes de programas masivos de regularización migratoria que en esos Estados han beneficiado a los nicaragüenses.

En los Estados Unidos, la situación particular de los migrantes nicaragüenses no ha sido muy estudiada. Pero sí lo ha sido en abundancia la situación de los latinos y ciertos tópicos de la situación del conjunto de centroamericanos. Abundan testimonios sobre su difícil situación. Son muchos los problemas que enfrentan los migrantes asentados tanto en Costa Rica como en los Estados Unidos: elevados costos de los servicios consulares, discriminación, problemas de adaptación sociocultural, escasa comunicación con sus familiares, carencia de documentos, informalidad laboral, bajos salarios, acceso a servicios sociales, entre otros 
Muchas también pueden ser las soluciones. Los consulados podrían ofrecer variados servicios con apoyo de la sociedad civil: información, tramitación de cédula de identidad y permisos, fomento de organizaciones de migrantes, denuncias antes el Ministerio del Trabajo y las instituciones que defienden los derechos humanos Existen experiencias exitosas de los consulados de otros países centroamericanos. El Programa de Atención de Comunidades de Salvadoreños en el Exterior, adscrito al Ministerio de Relaciones Exteriores, pretende facilitar mecanismos de comunicación, trabajo conjunto y protección del gobierno salvadoreño a sus coterráneos.

Los derechos humanos aparecen como un reto de los países emisores y receptores. Son un reto para el gobierno de Nicaragua. Como gobierno de un país emisor de migrantes, debe velar por la situación de sus ciudadanos. Como gobierno de un país de tránsito y receptor de migrantes, debe garantizar los derechos humanos de quienes se asientan en su territorio.

Conviene también tener presente el potencial de desarrollo que muestran las redes y comunidades transfronterizas, su fomento y aprovechamiento productivo debe ser un punto de agenda en las negociaciones binacionales. La región fronteriza binacional de Nicaragua y Costa Rica es paradigmática en este sentido. Sus pobladores, independientemente de en cuál lado de la línea divisoria tengan su domicilio, comparten familiares de ambas nacionalidades, intereses ambientales, relaciones comerciales y uso de los servicios públicos de ambos países. El reconocimiento formal de esta situación, que ha consagrado un espacio binacional fecundo en interrelaciones, puede ser un paso hacia una serie de programas sinérgicos conducidos por los gobiernos locales.

\section{Base institucional y líneas de acción en el sector público}

La posibilidad de ratificar los tratados internacionales referentes a las migraciones, de adecuar la legislación nacional a dicha normativa y de aplicarla de manera efectiva, descansa sobre un tejido multi-institucional. Sólo esa urdimbre puede posibilitar el diseño de programas que incidan simultáneamente sobre varias aristas del fenómeno migratorio, y llevar a efecto una gestión que aborde la mayoría de los aspectos cuyo tratamiento podría mitigar los efectos adversos y multiplicar los efectos benéficos de las migraciones.

A fin de caminar en esa dirección, es necesario que cada entidad disponga de un plan de acción que incluya tareas bien definidas y que los planes de acción de todas las instituciones implicadas en la gestión migratoria sean complementarios y contemplen la coordinación de actividades. Aquí únicamente proponemos un modelo de cómo podrían distribuirse algunas funciones, competencias y tareas. Se trata de una propuesta preliminar, cuya mayor elaboración debe ser el producto del diálogo entre diversas entidades y la consulta con migrantes.

Las funciones que a continuación se mencionan han sido distribuidas a partir de competencias formalmente establecidas. Su distribución es un paso para jerarquizar las coordinaciones necesarias y garantizar un conjunto articulado de acciones que atiendan al volumen de los movimientos migratorios y a los factores que condicionan dichos movimientos, que se vinculen a los planes nacionales de desarrollo, que apliquen la legislación internacional migratoria y propicien su adopción en el cuerpo jurídico nacional, que aprovechen las competencias 
y potencialidades de las organizaciones nacionales, que atiendan a los diversos tipos de migrantes y sus requerimientos, que incidan sobre la percepción dominante en torno a las migraciones y que multipliquen los vínculos existentes y posibles entre el sector público y las organizaciones no gubernamentales. En este sentido, las instituciones son los nudos de una política migratoria que comprende leyes, objetivos, coordinaciones y programas de actividades.

\subsection{Ministerio de Relaciones Exteriores}

En relación a las migraciones, la ley establece que al Ministerio de Relaciones Exteriores le corresponde formular, proponer y ejecutar la política exterior del Estado; organizar, acreditar, dirigir y supervisar las misiones diplomáticas, representaciones permanentes, oficinas consulares y misiones especiales; proteger los intereses de los nicaragüenses en el exterior; negociar y suscribir por delegación expresa del Presidente de la República instrumentos jurídicos internacionales y depositar los instrumentos de ratificación correspondientes; y coordinar con el Ministerio de Gobernación las políticas y normas de migración a ser aplicadas por las misiones diplomáticas y oficinas consulares en el exterior. ${ }^{5}$

Por consiguiente, el Ministerio de Relaciones Exteriores es una entidad con un rol protagónico en el cumplimiento de lo establecido por el artículo 65 de la Convención internacional sobre la protección de los derechos de todos los trabajadores migratorios y de sus familiares: "Los Estados Partes mantendrán servicios apropiados para atender las cuestiones relacionadas con la migración internacional de trabajadores y sus familiares. Sus funciones serán, entre otras: a) La formulación y la ejecución de políticas relativas a esa clase de migración; b) El intercambio de información, las consultas y la cooperación con las autoridades competentes de otros Estados Partes interesados en esa clase de migración..." (ACNUR et al., 2002:265).

La ley de Servicio Exterior en su artículo 4 establece que el Ministerio de Relaciones Exteriores, por medio de su Servicio Exterior, deberá "proteger los intereses nacionales del Estado, y los derechos fundamentales de los nicaragüenses en el extranjero; de conformidad con la Constitución Política de la Nación, la legislación nacional y con las normas y los principios del Derecho Internacional”. ${ }^{6}$ Por su parte, el artículo 28 de la Constitución Política de Nicaragua señala que "los nicaragüenses que se encuentren en el extranjero gozan del amparo y protección del Estado, los que se hacen efectivos por medio de sus representaciones diplomáticas y consulares”. Estas obligaciones son parte de los compromisos que adquieren los Estados firmantes de la Convención internacional sobre la protección de los derechos de todos los trabajadores migratorios y de sus familiares, según reza el inciso 2 del artículo 65: "Los Estados partes facilitarán, según corresponda, la provisión de servicios consulares adecuados y otros servicios que sean necesarios para atender a las necesidades sociales, culturales y de otra índole de los trabajadores migratorios y sus familiares" (ACNUR et al., 2002:265).

El Ministerio de Relaciones Exteriores podría ser una instancia clave en la coordinación del resto de organismos involucrados en la gestión de las migraciones y una de las que mayores vínculos mantenga con instituciones de la sociedad civil. Como entidad gestora de 
las relaciones internacionales del Estado de Nicaragua, le corresponden funciones vitales en una política migratoria. La adopción de la legislación internacional en el cuerpo legal nicaragüense es un proceso que requiere capacidad técnica y voluntad política. El Ministerio de Relaciones Exteriores podría ser un agente clave en dicho proceso, así como en las negociaciones y suscripción de convenios con los países relacionados con la emigración de nicaragüenses. Fortalecer los consulados de los países de tránsito y destino, difundir información sobre las migraciones y coordinar la protección de los derechos humanos de los migrantes con la Procuraduría para la Defensa de los Derechos Humanos son algunas de las acciones de mayores consecuencias que este ministerio podría emprender.

En algunas de estas acciones, como en el fortalecimiento de la gestión consular para la creación de consulados móviles, la colaboración con organismos de la sociedad civil ha mostrado ser especialmente benéfica. Las principales líneas de trabajo a emprender podrían desglosarse en:

- Impulsar el proceso de adecuación de la legislación nacional a la Convención internacional sobre la protección de los derechos de todos los trabajadores migratorios y de sus familiares.

- Suscribir acuerdos con los Estados donde residen o transitan nicaragüenses para regular los flujos, disminuir riesgos del tránsito, evitar que se prolongue la detención, garantizar el respeto a la persona y propiedad de los deportados nacionales y extranjeros, velar por un retorno digno y obtener información estadística actualizada. Indudablemente, en esta línea de trabajo, le corresponde un rol protagónico a la Directora General Consular y a la Dirección de Protección a Nacionales, conforme a lo establecido en el artículo 63 del reglamento de la Ley 290, que asigna a dicha dirección la misión de "brindar atención y asesoría a funcionarios del Servicio Exterior en la solución de casos de protección a nacionales" y "brindar asesoría legal en casos en los que se presuma que sus derechos humanos han sido o están siendo violados".7

- Establecer comisiones binacionales (Nicaragua y Costa Rica, Nicaragua y los Estados Unidos) y regionales (Centroamérica y los Estados Unidos) para la negociación de acuerdos en torno a los eventos e instrumentos asociados a las migraciones: amnistías, procedimientos para la detención y deportación de indocumentados, estatus de protección temporal, mecanismos periódicos de inserción de trabajadores temporales, transferencia de remesas, garantía de derechos humanos de los migrantes, protección especial para la niñez y adolescencia, programas de reunificación familiar, repatriación de nacionales fallecidos en el extranjero, entre otros. La Conferencia Regional sobre Migración (CRM) es una instancia privilegiada para este tipo de negociaciones.

- Fomentar y participar en comisiones multinacionales (Centroamérica y México) para gestionar políticas de atención a los migrantes en tránsito. Se trata de articular una coalición sobre la base de intereses comunes.

- Ejecutar un programa de protección consular para garantizar el respeto a los derechos de los migrantes nicaragüenses en los países de tránsito y destino. Parte de ese programa, 
en colaboración con el Consejo Supremo Electoral, debe agilizar la tramitación de cédulas. La apertura de consulados móviles es un hecho reciente, un gran paso para impulsar la documentación de nicaragüenses en Costa Rica y una pieza vital de las políticas migratorias.

- Fomentar las asociaciones de migrantes nicaragüenses a través de los consulados y de instituciones de la sociedad civil de los países de destino. Mantener una estrecha relación con dichas asociaciones y canalizar sus demandas hacia las instituciones relevantes. En este sentido, el Ministerio de Relaciones Exteriores desempeñará un rol vinculante con la comunidad migrante.

- En coordinación con el Ministerio del Trabajo, ejecutar programas para que las migraciones laborales temporales se realicen de manera ordenada y sin peligro para los migrantes. Esos programas incluirían la negociación de cuotas de trabajadores temporales, la difusión en Nicaragua de información referente a oportunidades de trabajo temporal en el exterior, el establecimiento y verificación de requisitos para aplicar a los programas, la tramitación de la incorporación a los programas y el monitoreo del ejercicio de los derechos de los migrantes. ${ }^{8}$

- Diseño y ejecución de mecanismos de coordinación entre las oficinas consulares y la Procuraduría de los Derechos Humanos para tramitar denuncias de violación de derechos humanos. La Procuraduría es la instancia a la que corresponde la defensa de los derechos humanos. Pero debido a sus limitaciones de presupuesto y personal, el apoyo de los consulados puede constituir un refuerzo particularmente benéfico.

- Difusión de información en torno a las migraciones: estadísticas migratorias de Nicaragua y los principales países de destino, derechos de los migrantes, políticas migratorias de Nicaragua y los principales países de destino, programas de migraciones temporales, organismos a los que pueden acudir los migrantes para defender sus derechos en los países de destino y tránsito, programas de protección consular, programas y acuerdos de la CRM y la OCAM, acuerdos con los países de destino y avances del trabajo de las comisiones binacionales.

- Negociar con sus homólogos de Costa Rica la definición de las sanciones que serían aplicadas a quienes atenten contra los extranjeros.

\subsection{Dirección General de Migración y Extranjería}

Como entidad responsable de la emisión de pasaportes y del registro, estadísticas y trámites migratorios y su homogeneización en el área centroamericana, la Dirección General de Migración puede estudiar y proponer modificaciones a la normativa en materia de migraciones, garantizar que la misma sea compatible con cuerpos legales referidos a otras materias, precisar y agilizar los procedimientos burocráticos de los diversos trámites que le competen, generar información y capacitar a sus funcionarios para que desarrollen sensibilidad y profesionalismo en el trato con los migrantes y las variadas problemáticas migratorias. 
La Dirección General de Migración y Extranjería podría poner énfasis para:

- Revisar y proponer modificaciones a las normas migratorias vigentes para adecuarlas a los instrumentos legislativos internacionales de protección a los derechos humanos de los migrantes.

- En el marco de la OCAM, establecer y difundir claros procedimientos burocráticos para el flujo seguro y ordenado de los migrantes laborales temporales, los deportados por tierra, los menores en proceso de reunificación familiar y los fallecidos a ser repatriados, de modo que las arbitrariedades, incertidumbres y riesgos se reduzcan al mínimo.

- Mantener una base actualizada de datos de inmigrantes y emigrantes en el marco del SIEMCA y difundir esa información, especialmente entre las instancias gubernamentales y no gubernamentales que apoyan la ejecución de una política migratoria.

- Habilitar los puntos legales de entrada y salida del país con personal capacitado tanto en diversos campos temáticos relativos a las migraciones internacionales como en relaciones humanas. Garantizar una capacitación permanente de sus funcionarios, con énfasis en derechos humanos, trata y tráfico ilegal, mercados laborales regionales y protección especial a niñez y adolescencia, a las mujeres y a los migrantes extraregionales en tránsito.

- Velar por que las zonas de asentamiento de los migrantes retornados sean compatibles con el Plan de Desarrollo Nacional y el manejo de áreas protegidas con propósitos ambientalistas.

\subsection{Ministerio del Trabajo}

Al Ministerio del Trabajo, entre otras funciones, le corresponde coordinar y ejecutar la política del Estado en materia laboral, velar por el cumplimiento de las normas y convenios internacionales de la OIT, brindar asesoría legal gratuita a los trabajadores involucrados en conflictos laborales individuales o colectivos, dirigir investigaciones específicas en el campo laboral y promover programas de capacitación a trabajadores y empleadores sobre los derechos, deberes, normas y procedimientos en materia de su competencia..$^{9}$ La aplicación de algunas de estas funciones al terreno de las migraciones internacionales supone una mayor especificación de las mismas y la coordinación con diversos organismos. Esas especificaciones podrían implicar que el Ministerio del Trabajo asuma algunos de los servicios que la Convención internacional sobre la protección de los derechos de todos los trabajadores migratorios y de sus familiares describe en su artículo 65: El suministro de información apropiada, en particular a empleadores, trabajadores y sus organizaciones, acerca de las políticas, leyes y reglamentos relativos a la migración y el empleo, los acuerdos sobre migración concertados con otros Estados y otros temas pertinentes; el suministro de información y asistencia apropiada a los trabajadores migratorios y sus familiares en lo relativo a las autorizaciones y formalidades y arreglos requeridos para la partida, el viaje, la llegada, la estancia, las actividades remuneradas, la salida y el regreso, así como en lo relativo a las condiciones de trabajo 
y de vida en el Estado de empleo, las normas aduaneras, monetarias y tributarias y otras leyes y reglamentos pertinentes (ACNUR et al., 2002:265).

La experiencia previa en relación a las migraciones laborales temporales puede proporcionar insumos valiosos para darle un carácter institucional a los convenios y mecanismos exitosos, de modo que superen su carácter episódico y proporcionen una plataforma propicia para reproducir y avanzar más allá de dichas experiencias.

En el marco de las actuales iniciativas de suscribir un convenio en torno a las migraciones temporales con su homólogo costarricense, el Ministerio del Trabajo podría:

- Informar sobre la situación socio-económica -y particularmente salarial y de acceso al sistema de seguridad social del país receptor- de los emigrantes nicaragüenses. Esto incluye el procesamiento de los censos y encuestas de los países de destino, la sistematización de investigaciones relevantes y noticias y el análisis a partir de censos y encuestas nacionales.

- Impulsar el proceso de ratificación y monitoreo del cumplimiento de las convenciones de la OIT que afectan a los trabajadores migrantes.

- Normar y operativizar las migraciones temporales de modo que se realicen de forma segura, ordenada y documentada, negociando cuotas y períodos para trabajadores temporales. Suscribir acuerdos con empresarios delos países receptores o potencialmente receptores. De acuerdo al artículo 242 del Reglamento de Ley de organización, competencia y procedimientos del poder ejecutivo, corresponde a la Dirección General de Empleo y Salarios del Ministerio del Trabajo dirigir y coordinar "la ejecución de convenios de migración de mano de obra para la colocación de trabajadores en otros países". ${ }^{10}$

- Capacitar a los potenciales migrantes temporales en relación a los derechos, deberes, normas y procedimientos en materia laboral de los países de destino previstos.

- Ofrecer información a los migrantes retornados para facilitar su reinserción laboral.

- Gestionar un convenio con las instituciones de seguridad social de los países receptores a fin de que los migrantes coticen en dichas instancias y éstas le retribuyan en relación a su aporte y a lo normado por la legislación de dichos países. Dada la complejidad de este tema, derivada de la extendida crisis de las instituciones de seguridad social, las controversias acerca del papel de los migrantes en esa crisis en países receptores, el relativamente bajo número de cotizaciones y la existencia de diversos modelos de seguridad social, es preciso que el Ministerio del Trabajo acopie más información y realice un análisis en torno a estas problemáticas y sus implicaciones para viabilizar convenios en torno a la seguridad social. 


\subsection{Procuraduría para la Defensa de los Derechos Humanos}

La Procuraduría para la Defensa de los Derechos Humanos puede aprovechar su alto grado de credibilidad para tener una mayor libertad de denuncia y proposición. De acuerdo a sus funciones, su trabajo se concentraría en acciones que repercutirían en las condiciones de los migrantes nacionales y extranjeros:

- Estudio para adecuar la legislación nacional a los requerimientos de la Convención internacional sobre la protección de los derechos de todos los trabajadores migratorios $\mathrm{y}$ de sus familiares.

- Monitoreo del ejercicio de los derechos humanos de los migrantes en tránsito y establecidos en otro país, prestando especial atención a los menores de edad y las mujeres. Posibilidad de coordinar acciones con sus homólogos en los países de tránsito y destino de los migrantes nicaragüenses.

- Monitoreo y defensa de los derechos humanos de los extranjeros que residen en Nicaragua o transitan por su territorio. El monitoreo implica obtener información del Ministerio del Trabajo, organizaciones no gubernamentales, medios de comunicación, asociaciones de migrantes y sindicatos.

- Coordinar trabajos con organismos de la sociedad civil especializados en protección de los derechos humanos y con aquellos que trabajan con migrantes y tienen capacidades de monitorear del ejercicio de sus derechos (debido a su trabajo directo con ellos), experiencia en comunicación o inversión en materiales que contienen información sobre los derechos de los migrantes.

\subsection{Ministerio de Educación}

Basándose en sus funciones de proponer los programas de educación nacional, formular propuestas sobre normas del proceso educativo y regular la política común de títulos además de su expedición y registro- ${ }^{11}$ y extendiendo dichas funciones al tema migratorio y a las relaciones con Costa Rica, el Ministerio de Educación puede trabajar en cuatro vías:

- A partir del análisis de estadísticas sobre los niveles y condiciones de escolaridad de los migrantes, realizar un trabajo conjunto con el Ministerio de Educación de Costa Rica, para asegurar el acceso de los migrantes nicaragüenses a la educación y el reconocimiento de los títulos académicos en el mercado laboral costarricense. Para cumplir este cometido, deberá agilizar los trámites de títulos académicos y negociar criterios para su homologación. De forma consecuente con esta línea de trabajo, debe procurar que los extranjeros residentes en Nicaragua tengan igualdad de condiciones de acceso a la educación.

- Sensibilizar sobre el impacto de la migración. Introducir en el pensum de los colegios y universidades temas para generar conciencia sobre las migraciones, especialmente entre los potenciales migrantes. Un tema clave será la desintegración familiar, para cuyo tratamiento deberá establecer coordinación con el Ministerio de la Familia. 
- Lucha contra la xenofobia en Costa Rica: negociar con sus homólogos de Costa Rica temas que aborden la imagen del nicaragüense en ese país.

- Garantizar en Nicaragua el acceso a la educación de los hijos de los trabajadores migratorios, de conformidad al compromiso que Nicaragua adquirió al ratificar la Convención internacional sobre la protección de los derechos de todos los trabajadores migratorios y de sus familiares, cuyo artículo 30 estipula que "Todos los hijos de los trabajadores migratorios gozarán el derecho fundamental de acceso a la educación en condiciones de igualdad de trato con los nacionales del Estado de que se trate. El acceso de los hijos de trabajadores migratorios a las instituciones de enseñanza preescolar o las escuelas públicas no podrá denegarse ni limitarse a causa de la situación irregular en lo que respecta a la permanencia o al empleo de cualquiera de los padres, ni del carácter irregular de la permanencia del hijo en el Estado de empleo" (ACNUR et al., 2002:251).

\subsection{Ministerio de Salud}

La política pública relacionada al crecimiento poblacional se torna especialmente importante en municipios expulsores, donde la tasa de crecimiento puede ser descendente. La descentralización e inversión sectorial que propugna el Plan Nacional de Desarrollo puede buscar impactos específicos sobre los municipios con ciertas características en su dinámica demográfica. Por su parte, el Ministerio de Salud podría aplicar programas considerando los períodos de movilidad y retorno de la población local migrante, a fin de que las labores de prevención e incluso las metas de control o eliminación de algunas enfermedades puedan ser alcanzadas. En el marco del Plan Nacional de Desarrollo, los migrantes podrían ser considerados un sector poblacional vulnerable al que se debe priorizar, poniendo especial énfasis en las mujeres en edad fértil, los adolescentes y los niños (Gobierno de Nicaragua, 2005).

La educación sexual en adolescentes y jóvenes es importante, orientada a la salud sexual y reproductiva, para asegurar el control de pandemias como el SIDA, que aumentó su tasa de incidencia de 0.62 a 1.5 por cien mil habitantes entre 1998 y 2001 (Gobierno de Nicaragua, 2005). La transmisión del VIH/SIDA y el acceso a los servicios de salud por parte de los migrantes son los dos temas que más vinculan la salud a las migraciones. Existen otras áreas en las que la intervención del Ministerio de Salud podría ser especialmente benéfica, como la atención psicosocial a niñez y adolescencia en situaciones de desintegración familiar y estrés asociados a las migraciones. La problemática psicosocial vinculada a los procesos de adaptación se agudiza especialmente cuando los migrantes se insertan en ambientes que les son hostiles y que les exigen un sobre esfuerzo de adaptación a cambios culturales.

De forma consecuente con estas opciones, este ministerio debe procurar que los extranjeros residentes en Nicaragua tengan igualdad de condiciones de acceso a los servicios de salud, principio cuya aplicación requiere especial atención debido a que los migrantes emprenden un proceso de adaptación plagado de obstáculos. Este principio encuentra soporte en la Ley General de Salud (No.423), aprobada en 2002, que introduce cambios jurídicos para garantizar la equidad de la salud y la atención a la población más vulnerable (Gobierno de 
Nicaragua, 2005). Dicha ley en cierto modo anticipa el compromiso que adquirió el Estado de Nicaragua al ratificar la Convención internacional sobre la protección de los derechos de todos los trabajadores migratorios y de sus familiares, cuyo artículo 28 establece que "los trabajadores migratorios y sus familiares tendrán derecho a recibir cualquier tipo de atención médica urgente que resulte necesaria para preservar su vida o para evitar daños irreparables a su salud en condiciones de igualdad de trato con los nacionales del Estado de que se trate. Esa atención médica de urgencia no podrá negarse por motivos de irregularidad en lo que respecta a la permanencia o al empleo" (ACNUR et al., 2002:251).

Un tema a resolver es el procedimiento entre la Caja del Seguro Social de Costa Rica y el Instituto Nicaragüense de Seguridad Social, de modo que se garantice la atención de una población que fluye entre ambos países y la posibilidad de reembolso o transferencia de las cotizaciones. La posibilidad de acuerdos en esta área tiene un soporte jurídico internacional en el artículo 27 de la Convención internacional sobre la protección de los derechos de todos los trabajadores migratorios y de sus familiares:

1. Los trabajadores migratorios y sus familiares gozarán en el Estado de empleo, con respecto a la seguridad social, del mismo trato que los nacionales en la medida en que cumplan los requisitos previstos en la legislación aplicable de ese Estado o en los tratados bilaterales y multilaterales aplicables. Las autoridades competentes del Estado de origen y del Estado de empleo podrán tomar en cualquier momento las disposiciones necesarias para determinar las modalidades de aplicación de esta norma.

2. Cuando la legislación aplicable no permita que los trabajadores migratorios o sus familiares gocen de alguna prestación, el Estado de que se trate, sobre la base del trato otorgado a los nacionales que estuvieren en situación similar, considerará la posibilidad de reembolsarles el monto de las contribuciones que hubieren aportado en relación con esas prestaciones (ACNUR et al., 2002:250-251).

\subsection{Ministerio de la Familia}

El Ministerio de la Familia puede elaborar propuestas para la reunificación familiar y trabajar activamente en una campaña para sensibilizar en torno al tema de la desintegración familiar y sus consecuencias. Retomando los estudios ya realizados y el censo de 2005, este ministerio podría encomendar una investigación más amplia y presentar una valoración sobre la magnitud del fenómeno, su impacto y las posibilidades de mitigar sus secuelas perniciosas mediante una atención especial a los hijos e hijas de los migrantes en escuelas, asociaciones de mujeres y asociaciones de familiares de migrantes.

La importancia de esta línea de trabajo y su factibilidad encuentran terreno propicio en la determinación del Plan Nacional de Desarrollo de "establecer estrictos mecanismos de protección especial de niñas, niños, adolescentes y familias que viven el fenómeno de la migración, bien sea por la vía de sus progenitores, bien sea como migrantes" (Gobierno de Nicaragua, 2005). Tomando en consideración la gran acumulación de vulnerabilidades, puesto que a la pobreza se suma el estrés familiar ocasionado por el proceso migratorio, 
el Plan apunta la necesidad de establecer redes de servicios en territorios de mayor flujo de migración, suscribir convenios binacionales de reunificación familiar, asegurar las pensiones alimenticias a la niñez y adolescencia de familias migrantes y facilitar acceso a los mecanismos de protección especial a la población menor en situación de riesgo (Gobierno de Nicaragua, 2005).

Como entidad responsable de promover y defender la institución familiar, proponer y ejecutar políticas que ayuden a resolver en forma integral la situación de la niñez desvalida y abandonada, formar para el ejercicio de una maternidad y paternidad responsables, y organizar la ejecución de programas dirigidos a las comunidades más vulnerables, ${ }^{12}$ el Ministerio de la Familia puede jugar un papel clave en lo que el Plan Nacional de Desarrollo denomina "protección especial desde un modelo integrado de gestión social”, concebido como el desarrollo articulado de acciones que permitan la atención de la niñez y la adolescencia en situación de riesgo y su reintegración familiar y social. Esta misión se apoya en un modelo centrado en las necesidades, capacidades y oportunidades de niños, niñas y adolescentes afectados; en sus hogares; y en sus comunidades (Gobierno de Nicaragua, 2005).

En el caso de la desintegración familiar y la niñez y adolescencia colocados en situación vulnerable por efecto de las migraciones, se hace más evidente la necesidad de coordinar con otras organizaciones gubernamentales y no gubernamentales, nacionales y extranjeras, dado que las acciones a emprender implican convenios binacionales (en el caso de la reunificación familiar), trabajo con los medios de comunicación social y el Ministerio de Educación (en el caso de la campaña de sensibilización) y coordinaciones con organizaciones no gubernamentales, instituciones eclesiales, asociaciones de mujeres y familiares de migrantes, la Defensoría de los Habitantes de Costa Rica, la Procuraduría para la Defensa de los Derechos Humanos de Nicaragua e instituciones similares para monitorear y mitigar la vulnerabilidad y garantizar los derechos a los niños, niñas y adolescentes migrantes o familiares de migrantes.

La ratificación de la Convención internacional sobre la protección de los derechos de todos los trabajadores migratorios y de sus familiares compromete al Estado de Nicaragua con la reunificación familiar, pero no a los Estados de destino si no suscriben dicha Convención, ya que en su artículo 44 establece: 1.Los Estados Partes, reconociendo que la familia es el grupo básico natural y fundamental de la sociedad y tiene derecho a protección por parte de la sociedad y del Estado, adoptarán las medidas apropiadas para asegurar la protección de la unidad de la familia del trabajador migratorio. 2.Los Estados Partes tomarán las medidas que estimen apropiadas y entren en la esfera de su competencia para facilitar la reunión de los trabajadores migratorios con sus cónyuges o con aquellas personas que mantengan con el trabajador migratorio una relación que, de conformidad con el derecho aplicable, produzca efectos equivalentes al matrimonio, al igual que con sus hijos solteros menores de edad que están a su cargo (ACNUR et al., 2002:256).

\subsection{Consejo Supremo Electoral}

Muchos migrantes salen del país sin haber tramitado jamás la cédula que los acredita como ciudadanos nicaragüenses. La regularización del estatus de los migrantes que entraron a un 
país de forma indocumentada empieza por el trámite de la partida de nacimiento, la cédula de identidad y el pasaporte. A través de las delegaciones consulares de la Cancillería, el Consejo Supremo Electoral podría agilizar el trámite de la cédula de identidad.

El ejercicio del voto para los nicaragüenses con residencia en el extranjero es un tema que ocasionalmente aflora y que tiene un soporte jurídico en la Convención internacional sobre la protección de los derechos de todos los trabajadores migratorios y de sus familiares, que establece en su artículo 41 el derecho a la participación de los migrantes como electores y elegibles a cargos públicos: 1.Los trabajadores migratorios y sus familiares tendrán derecho a participar en los asuntos públicos de su Estados de origen y a votar y ser elegidos en elecciones celebradas en ese Estado, de conformidad con su legislación. 2.Los Estados de que se trate facilitarán, según corresponda y de conformidad con su legislación, el ejercicio de esos derechos (ACNUR et al., 2002:254).

La reciente experiencia mexicana sienta un precedente interesante en este ámbito. En junio de 2005, el Congreso mexicano aprobó el voto postal o voto de los residentes en el extranjero. La iniciativa, sin embargo, limita el voto desde el exterior a aquellos mexicanos que cuentan con credencial de elector y lo condicionan a una petición previa ante el Instituto Federal Electoral (IFE), organismo responsable de la organización de los comicios. Los migrantes no podrán votar por senadores ni diputados, federales o públicos. Tampoco por gobernadores ni presidentes municipales. El IFE asegura que en los Estados Unidos hay más de 4 millones de mexicanos con credencial de elector. Sondeos oficiales e independientes revelan que alrededor del 87\% de los mexicanos avecindados en suelo estadounidense dicen que votarían si tuvieran la oportunidad. En algunos Estados de México se han hecho avances notables. La Federación de Clubes Zacatecanos del Sur de California (FCZSC) fue la principal promotora de la Ley del Inmigrante, que en el 2004 modificó la Constitución estatal para dar cabida por vez primera en el país a diputados y alcaldes inmigrantes (García, 2005).

Al Consejo Supremo Electoral corresponde estudiar en detalle los mecanismos de concreción y costos de la votación de nicaragüenses en el exterior. La realización de tal empresa requiere mejorar los vínculos institucionales modificando la legislación e incrementar la capacidad técnica y dotación de recursos de algunos organismos, así como superar las limitaciones que imponen la condición de irregularidad de muchos migrantes y/o su carencia de la cédula de identidad.

\subsection{Policía Nacional}

Tanto para las migraciones temporales como para el trámite de una residencia permanente, el registro de policía es un paso de rigor. La Policía Nacional podría multiplicar los convenios, como el que actualmente está vigente con Cáritas, que permite a los migrantes obtener rápidamente el registro, de modo que se multiplique la eficiencia en el trámite de dicho documento y garantice que el mismo sea concedido únicamente a ciudadanos de reconocida buena conducta. Las asociaciones de migrantes y los organismos de la sociedad civil agrupados en redes de apoyo a los migrantes podrían funcionar como intermediarios y garantes en dicho proceso de tramitación. 
Por otra parte, la policía tiene un rol que cumplir en la protección de los derechos de los migrantes. Su labor se beneficiaría si logra afinar sus mecanismos de detección de traficantes que abusan de los migrantes, de quienes participan en el comercio de mujeres con fines sexuales y de los migrantes desaparecidos.

\subsection{Sector económico del Gabinete}

En su ejecución del Plan Nacional de Desarrollo, el sector económico del Gabinete podría desglosar más de qué forma ciertas estrategias contribuirán específicamente a la retención de la población potencialmente migrante y al aprovechamiento de los efectos benéficos de las migraciones, como la transferencia tecnológica y el uso de remesas. En principio, debe garantizar que los trabajadores migratorios ejerzan el derecho que les reconoce el artículo 47 de la Convención internacional sobre la protección de los derechos de todos los trabajadores migratorios y de sus familiares: 1.Los trabajadores migratorios tendrán derecho a transferir sus ingresos y ahorros, en particular los fondos necesarios para el sustento de sus familiares, del Estados de empleo a su Estados de origen o a cualquier otro Estado. Esas transferencias se harán con arreglo a los procedimientos establecidos en la legislación aplicable del Estado interesado y de conformidad con los acuerdos internacionales aplicables. 2.Los Estados interesados adoptarán las medidas apropiadas para facilitar dichas transferencias (ACNUR et al., 2002:257-258).

- El sector económico del Gabinete podría contribuir a valorar las inversiones en educación, alimentación y salud, que posibilitan las remesas familiares, como una inversión productiva, librándolas de la etiqueta peyorativa de remesas para el "autoconsumo". En el futuro, también podría promover las remesas o fondos colectivos, negociando mejores condiciones para quienes las envían. En este sentido, de manera directa podría intervenir en la búsqueda y habilitación de mecanismos para reducir costos en la transferencia de remesas.

El objetivo de adecuar los marcos regulatorios para facilitar el ingreso de las remesas a los circuitos financieros implica, por ejemplo, la oferta de nuevos productos financieros (crédito contra la recepción regular de remesas) y unas normas más flexibles para la clasificación de la cartera crediticia de los bancos. Ninguna institución financiera se sentirá estimulada a otorgar préstamos a receptores de remesas que las reciban regularmente como única o principal garantía mientras las actuales normas prudenciales de la Superintendencia de Bancos y otras instituciones financieras persistan y clasifiquen préstamos de esa naturaleza en la cartera de alto riesgo, obligando al incremento del capital en reserva provisional.

La región fronteriza de Nicaragua-Costa Rica podría ser objeto de atención especial como parte de un programa de desarrollo binacional del Ministerio de Economía y el Instituto de Fomento Municipal (INIFOM). Muchos de los trabajadores de esa región pueden ser ubicados en la categoría de trabajador fronterizo ${ }^{13} \mathrm{y}$, en caso de llevarse a cabo las negociaciones del caso, podrían beneficiarse, aun sin establecer su residencia habitual en un Estado, de los derechos que en su parte IV la Convención internacional sobre la protección de los derechos de todos los trabajadores migratorios y de sus familiares reconoce a los trabajadores migratorios y sus familiares que están documentados o se encuentran en situación regular, 
según lo establecido en el artículo 58 de dicha convención. El mismo derecho les corresponde, según el artículo 59, a los trabajadores de temporada. ${ }^{14}$ La concreción de estos derechos sólo se llevará a efecto en caso de que los Estados de Nicaragua y Costa Rica suscriban acuerdos binacionales o regionales que los reconozcan o en caso de que Costa Rica ratifique la citada convención.

\subsection{Instituto de Fomento Municipal (INIFOM)}

Dado que los efectos de las migraciones tienen un impacto territorial a veces muy claramente perceptible, las municipalidades y el Instituto de Fomento Municipal pueden jugar un papel protagónico en las políticas migratorias. Los municipios emisores de migrantes, cuando lindan con los países de destino, como ocurre en la frontera con Costa Rica, podrían establecer mancomunidades con los municipios fronterizos, basadas en diversas áreas de intereses comunes: protección del medio ambiente, control de la delincuencia, establecimiento de una zona de desarrollo binacional con un mercado laboral transfronterizo. En este último aspecto, los municipios de ambos países podrían ser un valioso punto de apoyo para los ministerios del trabajo en la ejecución y monitoreo de programas de migración laboral temporal. Una tarea elemental que se les presenta es la oferta de información útil sobre consecuencias, riesgos y derechos de los migrantes y sobre instituciones a las que pueden acudir en caso de atropello a sus derechos.

\subsection{Comisión Nacional de Población}

Por medio del Decreto $\mathrm{N}^{0} .71-2002,{ }^{15}$ el gobierno de Nicaragua creó la Comisión Nacional de Población (CNP), organismo colegiado de coordinación de las actividades destinadas al cumplimiento efectivo de los objetivos de la Política Nacional de Población y su Plan de Acción. Instalada oficialmente el 13 de agosto de $2002,{ }^{16}$ esa comisión es coordinada por la Secretaría de Coordinación y Estrategias de la Presidencia y está conformada por las siguientes entidades: Ministerio de Salud, Ministerio de la Familia, Ministerio del Ambiente y Recursos Naturales, Secretaría de la Juventud, Instituto Nicaragüense de la Mujer, Instituto Nicaragüense de Estudios Territoriales, Instituto Nicaragüense de Fomento Municipal, Instituto Nacional de Estadísticas y Censos, Instituto Nacional Tecnológico y Ministerio de Educación, Cultura y Deporte.

Entre las funciones que el Decreto $\mathrm{N}^{0} .71$ asignó a esta comisión se encuentra la de "asegurar la ejecución de la Política Nacional de Población y su Plan de Acción por las entidades públicas y privadas mediante la inclusión y/o coordinación de las actividades en sus propios planes y programas, los que deberán ser aprobados por el Gabinete Social, revisados y ajustados oportunamente". También se adjudicó a dicha comisión la promoción de "una permanente comunicación del gobierno con organismos no gubernamentales, nacionales o extranjeros y con instituciones internacionales, para gestionar la participación y la cooperación necesaria que aseguren su efectiva contribución al logro de los objetivos específicos determinados en la Política Nacional de Población y su Plan de Acción”.

En relación a las migraciones internacionales, la Política Nacional de Población recuerda el derecho constitucional de los nicaragüenses "a circular y fijar su residencia en cualquier 
parte del territorio nacional y a entrar y salir libremente del país". ${ }^{17}$ Pero su única valoración de las migraciones internacionales tiene un sesgo negativo: "La Política Nacional de Población aborda en su dimensión el problema de la migración internacional por significar esto una pérdida de recursos humanos, muchos de ellos calificados, lo cual influye en formanegativa en los esfuerzos por el desarrollo nacional" (Ministerio de Acción Social, 1996). Desde que se formuló esa política en 1996 hasta la fecha, los flujos migratorios internacionales se han incrementado significativamente, las políticas de los países receptores han cambiado y el conocimiento sobre los impactos de las migraciones ha experimentado sensibles avances que comportan una visión más compleja sobre las migraciones, tanto por la comprensión de la diversidad de sus efectos -benéficos y adversos- como por un amplio entendimiento de la multiplicidad de áreas de atención que reclaman y las potencialidades que hacen emerger. A la luz de los hallazgos de estudios nacionales e internacionales, la Comisión Nacional de Población puede formular las implicaciones que tiene para una actualización de la Política Nacional de Población, manteniendo muchos de sus principios como puntos de referencia. Por ejemplo, la preocupación por la desintegración familiar, que en aquel momento era una secuela del conflicto bélico, ahora se presenta como una de las consecuencias más dolorosas de la migración internacional. La Política Nacional de Población tenía presente velar por esa ruptura familiar que "ha generado grandes repercusiones en la formación de la niñez y ha dejado otro tanto en la orfandad y el abandono, inclinándose muchos de ellos al riesgo físico y social..." (MAS, 1996:51). La Comisión Nacional de Población, en ejercicio de sus atribuciones, podría iniciar un proceso de diálogo con organismos de la sociedad civil, para adecuar la Política Nacional de Población a los requerimientos del estado actual de las migraciones internacionales, tomando en cuenta las áreas en que dicha política enfocó sus propuestas -familia, salud sexual y reproductiva, educación, distribución poblacional- y agregando otras que respondan a efectos y situaciones novedosas. Algunos de esos efectos, como las remesas que envían los migrantes, fueron mencionados de manera meliorativa en el Plan de Acción de dicha política poblacional: "las remesas de los emigrantes representan un aporte importante para las familias nicaragüenses y tienen un impacto significativo sobre la economía nacional” (Comisión Nacional de Población del Gobierno de Nicaragua, 2001).

\subsection{Coordinaciones y jerarquías}

A fin de que las tareas propuestas se cumplan y estén imbricadas de forma armoniosa es preciso que existan coordinaciones y subordinaciones. La Ley de Organización, Competencia y Procedimientos del Poder Ejecutivo, y su reglamento, fijan algunas coordinaciones. Algunas de éstas las tienen la Secretaría Técnica y la Secretaría de Acción Social de la Presidencia (Artículos 15 y 16) para temas económicos y sociales respectivamente. Dicha ley y su reglamento también asignan funciones sobre información, suscripción de convenios y monitoreo de su ejecución, y establecen qué tareas corresponden a las divisiones de coordinación interinstitucional de cada entidad estatal. Por tanto, esa ley es un punto de referencia obligado para identificar tareas y responsabilidades sobre coordinaciones. Sin embargo, presenta dos limitaciones. Por un lado, en las tareas que requieren la participación de dos o más organismos, las jerarquías y subordinaciones no siempre están explícitamente establecidas. Por otro lado, las migraciones y sus requerimientos están haciendo surgir una demanda de más servicios y, por consiguiente, de las funciones a ellos vinculadas, aún no contemplados en cuerpo legal alguno. 
Si tomamos los derechos humanos, la desintegración familiar y las remesas y los mercados laborales como temas prioritarios, resultará que en cada área, la formulación y ejecución de políticas y programas deberá estar a cargo de la Procuraduría para la Defensa de los Derechos Humanos, el Ministerio de la Familia (en estrecha relación con el Ministerio de Educación y el Ministerio de la Salud), el Ministerio de Economía y el Ministerio del Trabajo respectivamente. Puesto que todos esos temas están muy relacionados con la documentación de los nicaragüenses en el extranjero y su estatus, el Ministerio de Relaciones Exteriores, coordinando con el Consejo Supremo Electoral, la Dirección General de Migración y la Policía Nacional, mantiene un papel clave.

Otro escenario consistiría en una reactivación del Foro Nacional para las Migraciones, que podría ser liderado por la Comisión Nacional de Población (CNP) y/o el Consejo Nacional de Planificación Económica y Social (CONPES). Una nueva versión de dicho Foro podría desglosar el trabajo en tres comisiones:

1. Comisión para el ejercicio de los derechos sociales de los migrantes, que incluiría entidades como el Ministerio de Salud, el Ministerio de la Familia, el Ministerio de Educación y la Procuraduría para la Defensa de los Derechos Humanos. Sus áreas de trabajo serían, entre otras, la reunificación familiar, la atención psicosocial a niñas y niños familiares de migrantes, la mayor vulnerabilidad de las mujeres que migran, la información sobre derechos sociales, el monitoreo del ejercicio de los derechos humanos, la salud sexual y reproductiva (con atención especial al VIH/SIDA), el acceso a la educación y el acceso a la salud.

2. Comisión de documentación y regularización migratoria, que estaría integrada por el Ministerio de Relaciones Exteriores, la Dirección General de Migración y Extranjería, el Consejo Supremo Electoral y la Policía Nacional. Se concentraría de forma prioritaria en los siguientes temas: negociación de amnistías migratorias, trámites de cédulas a nacionales en el extranjero, búsqueda de desaparecidos, tráfico de migrantes, información sobre riesgos y derechos de los migrantes, información sobre regularización migratoria, protección consular, deportaciones (a Nicaragua o desde Nicaragua) y participación electoral desde el extranjero.

3. Comisión de mercados laborales globalizados, que incluiría al Ministerio de Economía, el Ministerio del Trabajo y el Instituto de Fomento Municipal (INIFOM). Algunas de sus áreas de trabajo serían las remesas, los mercados laborales regionales y extraregionales, los convenios para trabajadores migrantes temporales y el desarrollo de las zonas fronterizas.

A estas comisiones podrían integrarse organismos de la sociedad civil, agencias de cooperación externa y organismos multilaterales de acuerdo a sus áreas de trabajo específicas. La definición más acabada de las subordinaciones y jerarquías podrá hacerse sobre la marcha, respondiendo a las demandas de servicios de parte de los migrantes y al liderazgo que las entidades ejerzan. También ponderar ulteriormente la conveniencia de definir eventuales desgloses o desmembramientos de comisiones, a medida que avance el trabajo y crezca la complejidad de las tareas. Esta distribución de temas y entidades por comisiones no impide el abordaje de un mismo tema o tarea por entidades de varias 
comisiones. Por ejemplo, las deportaciones demandan al menos la intervención del Ministerio de Relaciones Exteriores a través de sus delegaciones consulares y de la Procuraduría para la Defensa de los Derechos Humanos. El intercambio de información y la acción conjunta de organismos insertos en distintas comisiones deberían ser habituales y hacer ostensible la interrelación de las distintas áreas de acción. La división en comisiones debe proporcionar una estructura que no seccione la gestión migratoria en compartimentos estancos. La conexión del trabajo emana de la concatenación de los fenómenos que deben ser atendidos: el estatus legal tiene un impacto sobre el ejercicio de los derechos humanos y los mercados laborales y sus consecuencias roturan las vías de inserción socioeconómica, cultural y política de los migrantes en las sociedades de origen y destino.

\section{Notas}

1 Instituto Nacional de Migración, Secretaría de Gobernación de México, http://www.inm.gob.mx/paginas/estadisticas/ enedic03/ rechazos.mht y http://www.inm.gob.mx/paginas/estadisticas/eneago04/rechazos.mht

2 Dirección General de Migración y Extranjería, http://www.migracion.gob.ni/mostrar_estadisticas.php?ID=3 15/3/2005.

1523 Dirección General de Migración y Extranjeria, http://www.migracion.gob.ni/mostrar_estadisticas.php?ID=3 15/3/2005.

4 El 19 de marzo de 2004, la Sala Constitucional de la Corte Suprema de Justicia, por medio de la resolución 2004-02955, declaró con lugar el recurso que adujo que más de sesenta nicaragüenses, durante un operativo llevado a efecto el 30 de enero de 2004 en La Carpio, "fueron detenidos de forma arbitraria e injustificada como parte de un operativo ordenado ilegalmente por el Ministerio de Gobernación y Policía. Que además en el operativo se hicieron detenciones masivas y en muchas ocasiones se violentaron domicilios". Por medio de su resolución, la Sala Constitucional condenó "al Estado al pago de los daños y perjuicios causados con los hechos que sirven de base a esta declaratoria, los que se liquidarán en ejecución de sentencia de lo contencioso administrativo".

5 Artículo 19. Ley de organización, competencia y procedimientos del poder ejecutivo. Ley №.290, del 27 de marzo de 1998. La Gaceta №.102 del 3 de junio de 1998.

6 Artículo 4. Ley №.358, Ley de Servicio Exterior del 30 de agosto de 2000.

7 Decreto No.71-98. Reglamento a la Ley 290, ley de organización, competencia y procedimientos del poder ejecutivo, publicada en La Gaceta №.102, del 3 de junio de 1998.

8 En este caso, el artículo 63 del reglamento a la Ley 290 también establece que a la Dirección de Protección a Nacionales le corresponde "participar en la negociación, ejecución y supervisión de programas laborales para el exterior, que se organizan en Nicaragua a través de Convenios para trabajadores nicaragüenses".

9 Artículo 27. Ley №.290.

10 Artículo 242. Reglamento a la Ley 290.

11 Artículo 23. Ley 290.

12 Artículo 29. Ley 290.

13 De acuerdo al artículo 2 e inciso 2.a) de la Convención Internacional sobre la protección de los derechos de todos los trabajadores migratorios y de sus familiares "se entenderá por 'trabajador fronterizo' todo trabajador migratorio que conserve su residencia habitual en un Estado vecino, al que normalmente regrese cada día o al menos una vez por semana".

14 De acuerdo al artículo 2 e inciso 2.b) de la Convención Internacional sobre la protección de los derechos de todos los trabajadores migratorios y de sus familiares "se entenderá por 'trabajador de temporada' todo trabajador migratorio cuyo trabajo, por su propia naturaleza, dependa de condiciones estacionales y sólo lo realice durante parte del año".

15 Dado en la ciudad de Managua el 8 de agosto de 2002.

16 http://www.presidencia.gob.ni/Presidencia/files_index/presidente/Discursos/2002/agosto/13agosto.htm

17 Derecho consignado en el artículo 31 de la Constitución Política de la república de Nicaragua. 


\section{Referencias bibliográficas}

ACUÑA GONZÁLEZ, G. (2004). Diagnóstico. La agroindustria de la caña de azúcar en Costa Rica: características, organización y condiciones laborales, Asociación de servicios de promoción laboral, San José, Costa Rica: Mimeo.

ACUÑA GONZÁLEZ, G. \& OLIVARES FERRETO, E. (1999). La población migrante nicaragüense en Costa Rica: realidades y respuestas. San José: Fundación Arias para la Paz y el Progreso Humano, Centro de recursos para el desarrollo sostenible de los asentamientos humanos (CERCA).

ACNUR, UNIVERSIDAD IBEROAMERICANA \& COMISIÓN NACIONAL DE LOS DERECHOS HUMANOS (2002) "Principios y criterios relativos a refugiados y derechos humanos", Colección de instrumentos jurídicos internacionales relativos a refugiados, derechos humanos y temas conexos, Tomo I, México.

ALVARENGA VENUTOLO, P. (2000). "Trabajadores inmigrantes en la caficultura", Cuaderno de Ciencias Sociales $N^{o}$ 116, San José: Facultad Latinoamericana de Ciencias Sociales (FLACSO), Sede académica Costa Rica.

ASAMBLEA NACIONAL (1998) Ley de organización, competencia y procedimientos del poder ejecutivo. Ley No.290, del 27 de marzo de 1998. Managua: La Gaceta No.102 del 3 de junio de 1998.

BAUMEISTER, E. (2006). "Migración internacional y desarrollo en Nicaragua", Serie población y desarrollo, Managua: CELADE-CEPAL.

CAJA COSTARRICENSE DEL SEGURO SOCIAL (2004), Costa Rica. Impacto de las migraciones en los servicios públicos, San José: Dirección actuarial y de planificación económica.

CASTILLO, M. Á. (2000), "Las políticas hacia la migración centroamericana en países de origen, de destino y de tránsito", Papeles de POBLACIÓN, México: Centro de Investigación y Estudios de la Población (CIEAP), Universidad Autónoma del Estado de México (UAEM), No.24.

COMISIÓN ECONÓMICA PARA AMÉRICA LATINA Y EL CARIBE (CEPAL), ORGANIZACIÓN INTERNACIONAL PARA LAS MIGRACIONES (OIM), BANCO INTERAMERICANO DE DESARROLLO (BID), (2002). Informes nacionales sobre migración internacional en países de Centroamérica, Taller de capacitación para el análiss de información censal sobre migración internacional en América Central, Santiago de Chile.

COMISIÓN NACIONAL DE POBLACIÓN DEL GOBIERNO DE NICARAGUA (2001). Plan de Acción de la Política Nacional de Población, Managua, Nicaragua, julio.

CONSEJO NACIONAL DE PLANIFICACIÓN ECONÓMICA SOCIAL (CONPES), (2001). Nicaragua: migraciones externas, Managua, Nicaragua.

DIRECCIÓN GENERAL DE MIGRACIÓN Y EXTRANJERÍA (DGME), http://www.migracion. gob.ni/mostrar_estadisticas.php?ID=3 15/3/2005. Consultado: 20 de abril de 2006

GARCÍA ZAMORA, R. (2005). "Migración internacional y remesas colectivas en Zacatecas. Impactos y desafíos del Programa $3 \times 1$ ”, Foreing Affairs en español Vol.5 $\mathrm{N}^{\circ} 3$, Instituto Tecnológico Autónomo de México (ITAM), julio-septiembre.

GOBIERNO DE NICARAGUA (2005). Propuesta de Plan Nacional de Desarrollo, www.pnd. gob.ni. Consultado: 206 de abril de 2006.

IMMIGRATION AND NATURALIZATION SERVICE (1996, 1998, 1999, 2000, 2001, 2002, 2003, 2004). Statistical Yearbook of the Immigration and Naturalization Service, U.S. 
Department of Homeland Security.

INSTITUTO DE INVESTIGACIONES ITZTANI, (1989). "Refugiados y repatriación: el caso de los mískitos y sumus en Nicaragua y Honduras”, Director de la investigación: Marvin Ortega. Versión mimeo.

INSTITUTO NACIONAL DE MIGRACIÓN, SECRETARÍA DE GOBERNACIÓN DE MÉXICO (2003) www.inm.gob.mx/estadisticas/enedic03/rechazos.mht, www.inm.gob.mx/ estadisticas/eneago04/rechazos.mht. Consultado: 10 de febrero de 2008.

MÁRMORA, L. (2002). Las políticas de migraciones internacionales, Paidós, Buenos Aires.

MASSEY, D. S. \& ESPINOSA, K. E. (1997). "What's Driving Mexico-U.S. Migration? A Theoretical, Empirical, and Policy Analysis, American Journal of Sociology, Volume 102, Issue 4 (Jan., 1997). Pp. 939-999.

MINISTERIO DE ACCIÓN SOCIAL (MAS) (1996). Política Nacional de Población 1996, Managua, Nicaragua.

NYGREN, A. (2000). "Environmental Narratives on Protection and Production: Nature-based Conflicts in Río San Juan, Nicaragua”, Development and Change, Vol.31. Pp. 907-830.

OFICINA DE ORDENAMIENTO TERRITORIAL \& DANIDA (2000) "Proyecto manejo sostenible de la zona de amortiguamiento en la municipalidd 'El Castillo', Río San Juan”, junio. Mimeo.

ORGANIZACIÓN INTERNACIONAL DE LAS MIGRACIONES (OIM) (2005), "Acuerdos del grupo binacional Guatemala-México, sobre asuntos migratorios", Cuadernos de trabajo sobre migración No.10, Guatemala.

(2001), “Tráfico de migrantes. Estudio de caso: Nicaragua”, Managua, Nicaragua.

Organización Internacional para las Migraciones (OIM), (S.Fa), "Combatiendo la migración irregular y el Tráfico de migrantes: elementos de una respuesta”. Mimeo.

Mimeo.

(S.Fb), "Tráfico de Migrantes: Algunas Perspectivas Mundiales y Regionales".

(S.Fc), “Tráfico de Migrantes: Estudio de Caso Guatemala”. Mimeo.

(S.Fd), "Tráfico de Migrantes: Estudio de Caso El Salvador". Mimeo.

(S.Fe), "Tráfico de Migrantes: Estudio de Caso Honduras". Mimeo.

(S.Ff), "Tráfico Ilegal de Migrantes: Estudio de Caso Panamá". Mimeo.

OIM, DIRECCIÓN GENERAL DE MIGRACIÓN Y EXTRANJERÍA DEL MINISTERIO DE GOBERNACIÓN Y POLICÍA \& SEGURIDAD PÚBLICA DE COSTA RICA (2000). "Tráfico de migrantes. Estudio de caso: Costa Rica”, San José, Costa Rica.

SANDOVAL GARCÍA, C. (2004). "Contested Discourses on National Identity: Representing Nicaraguan Immigration to Costa Rica”, Bulletin of Latin American Research, Vol.23, No.4, pp.434-445. 